Medical Principles

and Practice

\section{Mariam H. Yousif \\ Olav Thulesius}

Department of Pharmacology and Toxicology, Faculty of Medicine, Kuwait University, Kuwait

\title{
Comparative Study of Meloxicam and Indomethacin on Ovine Ureteral Motility
}

\section{Key Words \\ Non-steroidal anti-inflammatory drugs COX-1 \\ COX-2 \\ Meloxicam \\ Indomethacin \\ Ureteral motility}

\begin{abstract}
Objective: To test the potentially toxic urinary tract effects of indomethacin in comparison with a novel COX-2 inhibitor, meloxicam. Method: In vitro experiments were performed using isolated ring segments of sheep ureter mounted in organ-baths. Changes in isometric tension and frequency of rhythmic contractions were assessed in control and lipopolysaccharide (LPS)-treated preparations prior to and after administration of the tested drugs. Results: Sheep ureteral rings displayed reproducible spontaneous rhythmic contractions which were abolished by indomethacin $\left(10^{-6} M\right)$ and not by meloxicam $\left(10^{-6} M\right)$ under control conditions. However, in LPS-treated preparations, to induce COX-2, meloxicam produced a slight inhibitory action. Conclusion: Indomethacin blocks normal motility through inhibition of COX-1, while meloxicam does not interfere with ureteral peristalsis. Meloxicam only exerts a slight inhibition in inflammation-induced preparations due to the specific action as an inhibitor of COX-2. Further studies are needed to evaluate and compare the effects of meloxicam and indomethacin from other measures of effects of COX-1 and COX-2.
\end{abstract}

\section{Introduction}

Prostaglandins or eicosanoids are not only involved in a large number of pathological conditions such as inflammation, pain and septic shock but also serve normal physiologi- cal processes like kidney function, blood clotting, parturition and gastro-intestinal function. Prostaglandin synthesis is governed by a key enzyme, cyclo-oxygenase (COX). New research has shown that it exists in two distinct isoforms: COX-1 and COX-2. COX-1 is a

\begin{tabular}{ll}
\hline KARGER & @ 1998 S. Karger AG, Basel \\
Fax +4161306 12 34 & 1011-7571/98/0073-0198\$15.00/0 \\
$\begin{array}{l}\text { E-Mail karger@karger.ch } \\
\text { www.karger.com }\end{array}$ & Accessible online at: \\
http://BioMedNet.com/karger
\end{tabular}

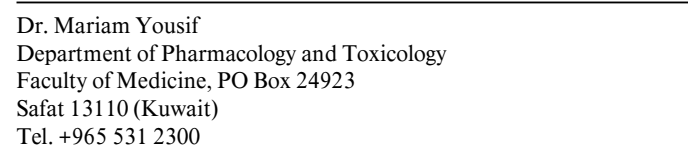


constitutive enzyme that is always present and responsible for the generation of small amounts of eicosanoids that govern normal organ function. COX-2 is induced by disease processes such as inflammatory stimuli and cytokines [1-5]. The therapeutic actions of non-steroidal anti-inflammatory drugs (NSAID) like aspirin and indomethacin depend on the inhibition of COX-2, whereas the undesirable side-effects such as gastric bleeding and nephropathy are due to inhibition of COX-1 [5]. This discovery has led to intense research to synthesize drugs that specifically inhibit COX-2 but not COX-1 in order to avoid adverse effects. One of the first of these drugs was meloxicam. Meloxicam is a new NSAID derived from enolic acid. The antiinflammatory potency of meloxicam in the rat is higher than that of well-established NSAIDs [6], and in vitro studies showed that meloxicam had no antagonistic properties against normal mediators [6, 7]. The spectrum of selective activities of the standard NSAIDs against the two enzymes ranges from a high selectivity for inhibiting COX-1 (e.g. indomethacin) to equal potency for inhibiting COX-1 and COX-2 (e.g. diclofenac) [8].

In this study, we have investigated the effects of meloxicam and indomethacin in vitro with a technique we previously described using ovine ureteral ring segments [911]. The aim of our study was to determine the specificity of meloxicam in inhibiting normal ureteral contractility in control preparations and those which were in vitro stimulated with the bacterial endotoxin lipopolysaccharide (LPS) to induce COX-2.

\section{Materials and Methods}

Male sheep kidneys with attached ureters were obtained from freshly slaughtered animals. Ureteral preparations were always taken from the same location. Rings of $4 \mathrm{~mm}$ length were cut and suspended in
Krebs-Henseleit solution at $\mathrm{pH} 7.4$ in 25 -ml organbaths aerated with $95 \% \mathrm{O}_{2}$ and $5 \% \mathrm{CO}_{2}$ at $37^{\circ} \mathrm{C}$. Isometric tension was recorded with UFI dynamometers and a Lectromed recorder system. The preparations were allowed to equilibrate under a pretension of 1.5$2.0 \mathrm{~g}$ for $30 \mathrm{~min}$ and during this period, the Krebs' solution was changed at 15 -min intervals. After establishing a stable pattern of rhythmic contractions, $250 \mu 1$ of bacterial endotoxin LPS was added to the organ-bath and left to incubate for $30 \mathrm{~min}$. Thereafter, meloxicam or indomethacin $\left(10^{-7}-10^{-6} M\right)$ was added to the bath in the presence of LPS. In control preparations, meloxicam or indomethacin $\left(10^{-7}-10^{-6} M\right)$ was also added to the organ-bath in LPS-free Krebs' solution.

\section{Data Analysis}

Changes in the frequency of rhythmic contractions per minute $(\mathrm{c} / \mathrm{min})$ were assessed by comparing the number of deflections during a 30-min period prior to and after administration of the tested drugs. Similarly, changes in tension $(\mathrm{g})$ were recorded as measured from the amplitude of the contractions. Data were analyzed using Graph-Pad PrismR. Results are presented as means \pm SE. Differences between mean values were tested for significance using Student's t test. Analysis was done using the Graphpad instat software. The difference was considered to be significant when the $\mathrm{p}$ value was less than 0.05 . The degree of significance is represented as follows: $* \mathrm{p}<0.05,{ }^{* *} \mathrm{p}<0.01$, and $* * * \mathrm{p}<0.001$.

\section{Drugs and Chemicals}

The composition of the Krebs-Henseleit solution was as follows (mM): $\mathrm{NaCl}(118.3), \mathrm{KCl}(4.7), \mathrm{CaCl}_{2}$ (2.5), $\mathrm{MgSO}_{4}$ (1.2), $\mathrm{NaHCO}_{3}(25), \mathrm{KH}_{2} \mathrm{PO}_{4}$ (1.2), and glucose (11.2). Indomethacin was obtained from Research Biochemicals International (RBI), Natick, Mass., USA, endotoxin (LPS) from Sigma Chemicals, St. Louis, Mo., USA. Meloxicam was a gift from Dr. Karl Thomae GmbH (Germany). Indomethacin was dissolved in methanol, while meloxicam in N,N-dimethyl formamide. The final concentration of the solvents in the organ-bath did not exceed $0.1 \%$, which had no effect on tissue contractility.

\section{Results}

In most of the experiments, the pattern of ureteral contractility was as shown in figure 1a. Except for few experiments, less than 
Fig. 1. Spontaneous rhythmic contractions of isolated sheep ureter rings in control conditions $(\mathbf{a}, \mathbf{b})$ and after incubation with LPS (c). Arrow indicates administration of $10^{-6} M$ indomethacin (a) and $10^{-6}$ $M$ meloxicam $(\mathbf{b}, \mathbf{c})$. Calibration of chart: horizontal $=4 \mathrm{~min}$; vertical $=$ $0.5 \mathrm{~g}$.

Fig. 2. Frequency of ureteral contractions under control conditions (untreated) and $30 \mathrm{~min}$ after administration of $10^{-6} \mathrm{M}$ meloxicam or $10^{-6} M$ indomethacin $(\mathrm{n}=6$; $* * * \mathrm{p}<0.001)$.
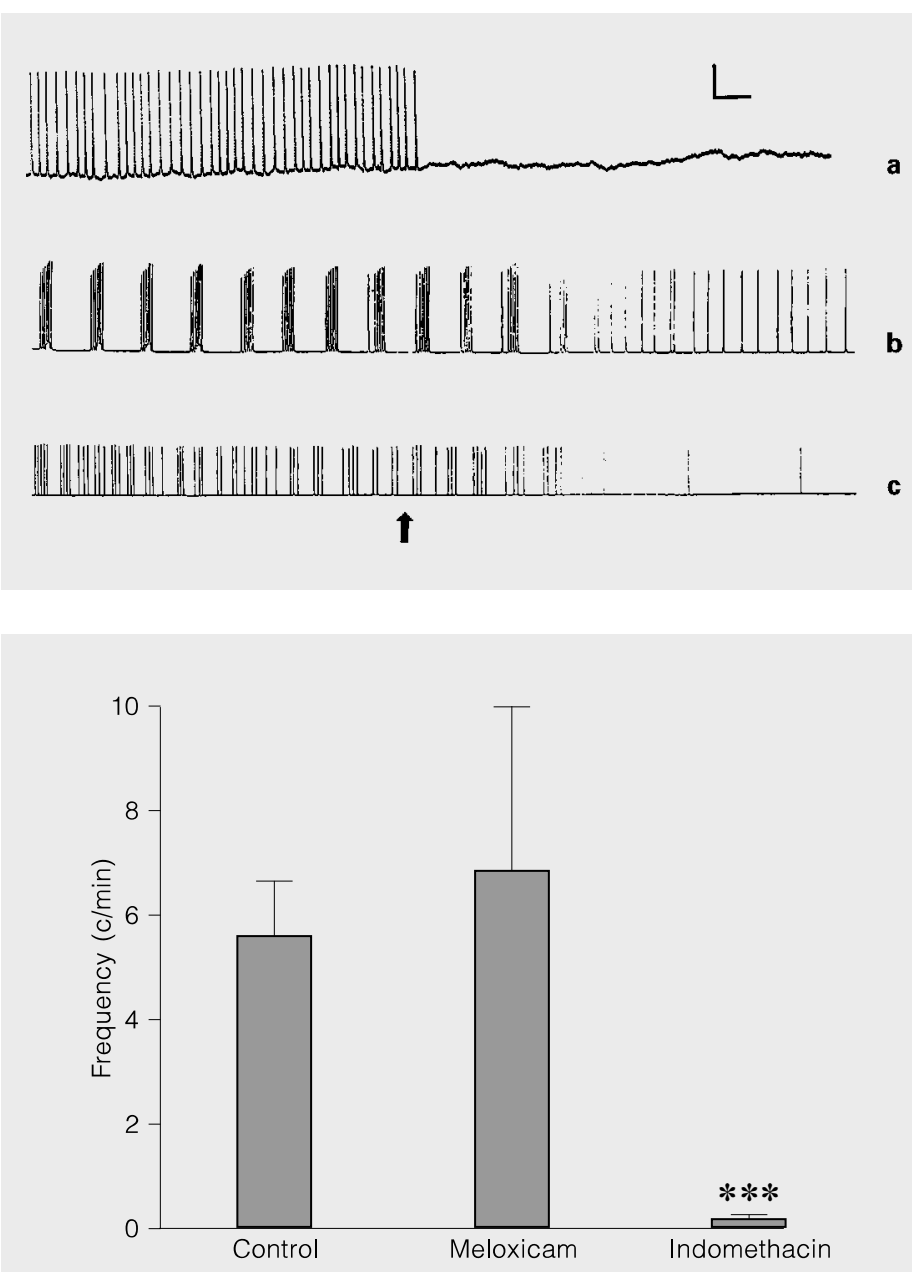

quickly stopped peristaltic activity. Meloxicam had no such effect. It only changed the pattern of motility, except in the preparation that was incubated with LPS. In this particular specimen there was a negative chronotropic effect, but no complete stoppage. The effect of meloxicam and indomethacin on the frequency of contractions with or without LPS is further demonstrated in the bar graphs of figures 2 and 3 . As can be seen in figure 2, treatment with indomethacin and not meloxicam 


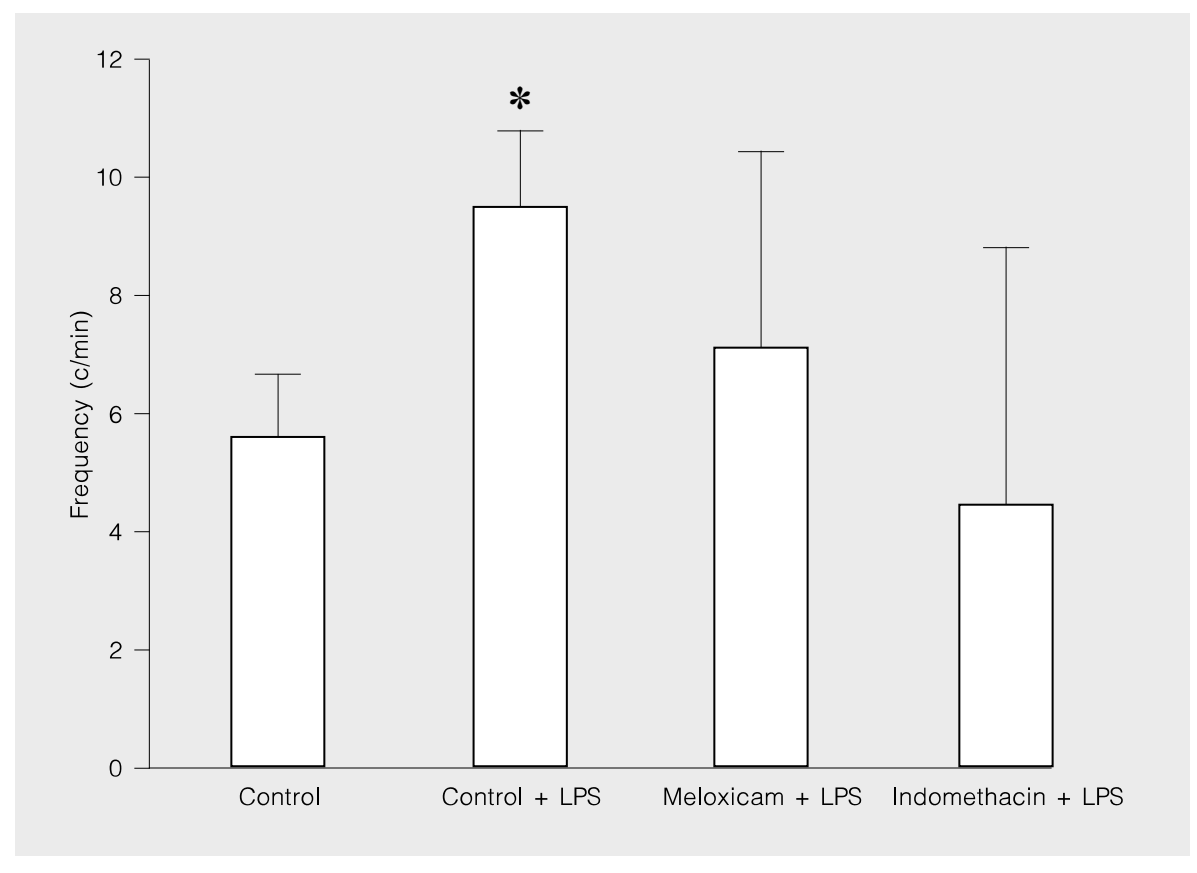

Fig. 3. Frequency of ureteral contractions before and after administration of LPS to the organ-bath, and $30 \mathrm{~min}$ after administration of $10^{-6} \mathrm{M}$ meloxicam or $10^{-6} \mathrm{M}$ indomethacin in the presence of LPS $\left(n=6 ;{ }^{*} p<0.05\right)$.

resulted in a significant reduction in peristaltic frequency $(\mathrm{p}<0.001)$. Figure 3 shows that the addition of $250 \mu 1$ LPS to the preparations significantly $(\mathrm{p}<0.05)$ augmented the frequency of contractions from $5.6 \pm 1.07$ to 9.4 $\pm 1.3 \mathrm{c} / \mathrm{min}$, which confirms our previous findings [12]. At the same time there was no significant change in amplitude (2.7 versus $2.5 \mathrm{~g}$, not shown graphically). As shown in figure 3, treatment with meloxicam and indomethacin in the presence of LPS resulted in some frequency reduction and the changes were not significant $(p>0.05)$.

\section{Discussion}

The COX enzyme is an integral membrane protein of the cell. COX-1 is present in most tissues and therefore called constitutive. It performs a normal 'housekeeping' function to synthesize prostaglandins which regulate cell activity and protects the organism. Vane and Botting [4] mention that in 1991 Xie et al. by chance discovered a new COX isoenzyme that is not normally active, but switched on or induced by various external inflammatory stimuli. This led to much further fruitful work and eventually resulted in the synthesis of a new enzyme, the COX-2 [4]. COX-2 is highly inducible by mediators of inflammation such as cytokines. The unwanted side-effects of the NSAIDs are thought to be due to inhibition of

Med Principles Pract 1998;7:198-202 
COX-1, while their primary anti-inflammatory effects are due to inhibition of COX-2. The practical consequences of this discovery is the prospect of finding new NSAIDs with selectivity for COX-2, which would eliminate toxicity. This development is already in process and has led to a number of new compounds with a promising profile of selectivity. One of them is meloxicam. This compound differs in its pharmacodynamic profile when compared to NSAIDs in current therapeutic use [6].

Ovine ureteral preparations produced reproducible rhythmic contractions. However, in few experiments, the pattern of contractility was different. The difference was not due to differences in the anatomical location of the isolated segments or to the solvents used. The reason for this difference is presently unknown.

In this study we have tested the ability of meloxicam in inhibiting ureteral contractions as compared with indomethacin under normal and inflammation-induced conditions.
The results show that under normal conditions, meloxicam did not affect the rhythmic contractions of the ureter. However, meloxicam only produced a slight inhibitory effect after inducing inflammation by the bacterial endotoxin LPS. In some of the preparations, it was noticed that indomethacin did not produce a complete inhibition of the ureteral contractions after incubation with LPS. Such observations gave an indication of the specificity of meloxicam in acting as a COX-2 and not COX-1 inhibitor. Therefore, meloxicam may provide an effective means for treatment of renal problems associated with inflammation, rather than using non-specific NSAIDs with the potential of greater side-effects such as reducing ureteral peristalsis [13].

The principle of testing the motility-inhibiting effect of NSAIDs on ureteral motility before and after treatment with LPS may be a useful assay for testing the specificity of COX-1 and COX-2 inhibitors.

\section{References}

1 Vane J: Towards a better aspirin. Nature 1994;367:215-216.

2 Vane JR, Botting RM: New insights into the mode of action of antiinflammatory drugs. Inflamm Res 1995;44:1-10.

3 Thulesius O: New non-steroidal anti-inflammatory drugs. J Kuwait Med Assoc 1996;28:407-410.

4 Vane JR, Botting RM: Mechanism of action of antiinflammatory drugs. Scand J Rheumatol 1996;102:9-21.

5 Mitchell JA, Akarasereenont $\mathrm{P}$, Thiemerman C, Flower RJ, Vane JR: Selectivity of nonsteroidal antiinflammatory drugs as inhibitors of constitutive and inducible cyclooxygenase. Proc Natl Acad Sci USA 1993;90:11693-11697.

6 Engelhardt G, Homma D, Schnitzler C, Utzmann R, Schlegel K: Antiinflammatory, analgesic, antipyretic and related properties of meloxi- cam, a new nonsteroidal anti-inflammatory agent. Inflamm Res 1995;44:423-433.

7 Engelhardt G, Bogel R, Schnitzler C, Utzmann R: Meloxicam: Influence on arachidonic acid metabolism. Part I: In vivo findings. Biochem Pharmacol 1996;51:21-28.

8 Engelhardt G, Homma D, Schlegel K, Schnitzler C, Utzmann R: General pharmacology of meloxicam. Part I: Effects on CNS, gastric emptying, intestinal transport, water, electrolyte and creatinine excretion. Gen Pharmacol 1996;27:673677.

9 Angelo-Khattar M, Thulesius O, Nilsson T, Cherian T, Joseph L: Motility of the human ureter, with special reference to the effect of indomethacin. Scand J Urol Nephrol 1985;19:261-265.
10 Thulesius O, Angelo-Khattar M, Ali M: The effect of prostaglandin synthesis inhibition on motility of the sheep ureter. Acta Physiol Scand 1987;131:51-54.

11 Bhargava KP, Thulesius O: Ovine ureteral motility as a new assay for the cyclo-oxygenase blocking potency of non-steroidal anti-inflammatory drugs. Gen Pharmacol 1987;18: 337-340.

12 Thulesius O, Araj G: The effect of uropathogenic bacteria on ureteral motility. Urol Res 1987;15:273276.

13 Khater S, Angelo-Kattar M, Thulesius $\mathrm{O}$ : The effect of indomethacin and metamizole on ureteral motility and urine flow in sheep. Urol Res 1990; 18:435-438. 